\title{
(Re)Escritas: reflexões do autor-leitor
}

\author{
Sabrina Alvernaz Silva Cabral
}

Colégio Pedro II - Rio de Janeiro

\begin{abstract}
Resumo
Interessados em discutir a leitura, escrita e reescrita por alunos de uma escola pública federal, buscamos promover o encontro desses com os contos da coletânea "Felicidade Clandestina" de Clarice Lispector e, dessa atividade, analisar as estratégias encontradas pelo autor-leitor na recriação de seu texto. As bases teóricas norteadoras deste trabalho estão pautadas no legado bakhtiniano, que sempre prevê o "outro" como interlocutor dialógico e a potência dos gêneros textuais que permeia toda a linguagem. Com relação aos resultados preliminares desta pesquisa, destacamos o quanto a reescrita se mostrou capaz de excitar a reflexão do aluno diante de sua produção e, ainda, o quanto a ocasião de se estimular a escrita de contos influenciados pela obra clariceana abre diversos caminhos criativos e interpretativos.
\end{abstract}

Palavras-chave: Gêneros Discursivos; Reescrita; Bakhtin

\begin{abstract}
In order to discuss students' reading, writing and rewriting at a federal public school, we attempt to set up a classroom situation in which they are introduced to Clarice Lispector's short story collection called Felicidade Clandestina and, from this activity, analyze the strategies found by the author-reader in the recreation of Lispector's texts. The theoretical bases guiding this study follow the Bakhtinian legacy, which predicts the "other" as a dialogical interlocutor and the power of the genres that permeate all language. Concerning the preliminary results of this research, we highlight how much the rewriting proved to excite students' thoughts about their production and, also, how much this occasion that stimulated short story writing, influenced by Clarice Lispector's work, opened several creative and interpretative paths.
\end{abstract}

Keywords: Discursive Genres; Rewriting; Bakhtin

\section{INTRODUÇÃO}

Este trabalho surge da experiência nascida em uma escola pública federal na cidade do Rio de Janeiro. As reflexões que propomos giram em torno do processo de leitura e (re)escrita por alunos a partir da coletânea "Felicidade Clandestina" de Clarice 
Lispector. Interessou-nos questionar: em que medida essa leitura provoca o amadurecimento da capacidade discursiva de alunos provenientes de práticas culturais de leitura tão distintas entre si? Quais são as estratégias de construção de sentido utilizadas por esses alunos? Como os saberes linguísticos e os conhecimentos de mundo são organizados para estabelecerem modos de interpretação e, ainda, produção escrita? Como os alunos ressignificam a obra, produzindo um texto inspirado em conto clariceano? Essas perguntas conduzem, então, uma pesquisa que tem por objetivo geral analisar o processo de aprofundamento na leitura e escrita de alunos diante do texto literário. É também nosso objetivo específico discutir a análise do aluno enquanto autor e leitor de seu próprio texto, após intervenção ou não pelo professor.

Partimos das concepções bakhtinianas de gêneros do discurso em que é impossível ao falante interagir no mundo sem lançar mão da estrutura composicional, das temáticas e do estilo de cada gênero, mesmo que esse interlocutor caminhe, em alguma medida, para as desconstruções provocadas por suas forças centrífugas. As distinções cunhadas por Marcuschi (2010) entre gênero e tipo aqui também são frutíferas, na medida em que auxiliam o aluno na compreensão das características internas do conto - a narração e a descrição.

Tal trabalho se justifica pela importância dada aos mecanismos de leitura e escrita no ambiente escolar e fora dele e também pelo valor da mediação pedagógica num processo que, muitas das vezes, é tortuoso para o aluno que chega ao Ensino Fundamental e Médio com diferentes competências linguísticas, em muitos casos aquém do que lhe são exigidas.

Marcos Bagno interessado em discutir "o que (não) ensinar na escola”, ressalta que "por trás do rótulo genérico língua se esconde um universo multidimensional de saberes, práticas, crenças, histórias, ritos, instrumentos, mecanismos de poder, papeis sociais, tradições culturais, para dizer o mínimo" (Bagno, 2012, p.28). É por esse viés que nós, professores de língua portuguesa, resgatamos a leitura e a escrita. Sem limitar o ensino dessas práticas a mero detalhamento gramatical ou terminológico, construímos uma percepção mais complexa daquilo que é um emaranhado de relações, funções, poderes e histórias. 


\section{PILARES TEÓRICOS}

Tomamos como base teórica que norteia este trabalho o legado conceitual de Mikhail Bakhtin e de Valentin Volóshinov¹.

Fiquemos com suas palavras: "a língua penetra na vida através dos enunciados concretos que a realizam, e é também através dos enunciados concretos que a vida penetra na língua" (2003, p.282) - publicadas no tão conhecido livro "Estética da criação verbal". Inspira-nos pensar no dinamismo da língua construído com "enunciados concretos" ou "enunciados relativamente estáveis" dos quais não podemos dispor.

Mais do que uma gramática com leis próprias, nos é dado, em nossas experiências de linguagem, certos modelos de textos sem os quais seria impossível a comunicação. Isto é, não precisamos inventar uma estrutura composicional a cada nova interação, porque já a herdamos em alguma medida. Quando arriscamos um diálogo, um depoimento ou um bilhete, trazemos conosco uma bagagem, muitas das vezes, não sistematizada quanto ao que mais tarde foi cunhado por Bakhtin como estilo, tema e estrutura composicional.

Os gêneros textuais, como se sabe, são ilimitados como são as atividades humanas. A cada nova necessidade, pode surgir um novo gênero e é também nesse sentido que a vida interpenetra na língua e a língua, na vida.

É difícil, após as muitas releituras do estruturalismo, imaginar a língua como sistema (forma $\mathrm{x}$ fundo) distanciado de seus falantes, de suas práticas sócio-discursivas e históricas. Somos nós, os sujeitos da língua, seus senhores e seus escravos. "Sujeitos", nos dois sentidos da palavra: tanto compreendido como o ser autônomo que constrói, age; e, ao mesmo tempo, entendido como indivíduo subordinado, o súdito ou o submisso frente às poderosas regras gramaticais ou discursivas. É nessa dualidade (aparentemente contraditória) que vamos tecendo linguagem, quer obedecendo expectativas, quer extrapolando-as.

Nesse intricado processo estão professores, ansiosos por ensinar, e alunos, ansiosos por acertar ${ }^{2}$. Cumprindo seus papéis sociais, caminham em direção a produzir

\footnotetext{
${ }^{1}$ A respeito desses teóricos, Marcuschi observa: "Durante algumas décadas, obras de autoria de Volóshinov e de Medvedev foram atribuídas a Bakhtin. Mais recentemente, no entanto, os estudiosos têm preferido devolver a autoria dessas obras a seus verdadeiros produtores. Volóshinov é o autor de pelo menos dois livros muito importantes e influentes: O freudismo (1927) e Marxismo e filosofia da linguagem (1929). Ambos têm publicação brasileira sob o nome de Bakhtin, embora na capa do segundo também apareça o nome de Volóshinov entre parênteses" (Marcuschi, 2010, p.55)
} 
textos verbais e escritos com finalidades diversas e múltiplas. É importante ressaltar, portanto, que consideraremos a linguagem por esse viés essencialmente discursivo que sempre prevê um "outro", escrevemos para alguém e sempre respondemos ativamente a uma questão e esperamos desse outro uma nova resposta.

Bakhtin, interessado em fazer crítica a alguns teóricos do século XIX, deferiu dura análise contra aqueles que não conseguiam entender a linguagem como radicalmente dialógica:

\begin{abstract}
A linguística do século XIX - a começar por W. Humboldt, sem negar a função comunicativa da linguagem, empenhou-se em relegá-la ao segundo plano, como algo acessório; passava-se para o primeiro plano a função formadora sobre o pensamento, independente da comunicação. Eis a célebre fórmula de Humboldt: "Abstraindo-se a necessidade de comunicação do homem, a língua lhe é indispensável para pensar, mesmo que tivesse de estar sempre sozinho." A escola de Vossler passa a função dita expressiva para o primeiro plano. Apesar das diferenças que os teóricos introduzem nessa função, ela, no essencial, resume-se à expressão do universo individual do locutor. A língua se deduz da necessidade do homem de expressar-se, de exteriorizar-se. A essência da língua, de uma forma ou de outra, resume-se à criatividade espiritual do indivíduo. Aventaram-se, e continuam-se a aventar, outras variantes das funções da linguagem, mas o que permanece característico é não uma ignorância absoluta, por certo, mas uma estimativa errada das funções comunicativas da linguagem; a linguagem é considerada do ponto de vista do locutor como se este estivesse sozinho, sem uma forçosa relação com os outros parceiros. (2003, p.289)
\end{abstract}

Trazemos para essa pesquisa esse importante princípio, já que não queremos pressupor que haja um aluno como indivíduo sozinho que quer exteriorizar-se, mas sim um aluno que responde ou reage ao texto, ao professor, aos seus pares.

Consideramos também outra questão: se alguns gêneros (até denominados por Bakhtin como "menos complexos", como "cartas" e "conversas") são mais facilmente dominados pelos falantes e escritores, outros são bem mais ariscos. Queremos nos debruçar sobre esses últimos para destrinchar suas partes e peculiaridades, para, então, melhor compreendê-los e produzi-los. Como exemplo desse segundo caso, citamos o conto literário.

Bagno (2012) também chama atenção para esse aspecto em sua "Gramática Pedagógica do Português Brasileiro":

[Ler e escrever] são práticas socioculturais que exigem um aprendizado relativamente longo e contínuo para que o aprendiz se apodere delas a ponto de exercê-las com habilidade e destreza. Sendo assim, o ensino da leitura e da

\footnotetext{
${ }^{2}$ Seguindo os princípios freirianos, diríamos: que bom seria se estivessem todos ansiosos por aprender!
} 
escrita, e o acesso aos discursos sociais que se valem delas, é a tarefa primordial da educação em língua materna na escola. (2012, p.29)

É por ser literatura e arte que o conto constitui em si uma proposta mais rebuscada, permeada por uma linguagem trabalhada e limada como o artífice faria com sua peça. Para continuar com Bagno, citamos:

É no trabalho com os mais variados gêneros textuais - falados e escritos que os aprendizes tomarão consciência da multiplicidade de usos possíveis da língua (...) é evidente que a literatura tem de se destacar na educação em língua materna (...) pelo que representa de fruição estética e de elemento constitutivo da cultura e da identidade de um indivíduo e da coletividade. (2012, p.32)

Este artigo, como anteriormente anunciado, quer se ater ao gênero textual conto e discutir como os alunos leram e interpretaram contos escritos por Clarice Lispector e como responderam a eles por meio de sua escrita e reescrita.

\section{METODOLOGIA}

Fizeram parte dos procedimentos metodológicos: promover a leitura e fomentar a discussão por adolescentes (alunos de uma escola pública federal na cidade do Rio de Janeiro no $8^{\circ}$ ano do Ensino Fundamental) de uma escritora que influencia inegavelmente o século XX e XXI, Clarice Lispector. Nosso escopo foi estimular diferentes possibilidades de interpretação; instaurar momentos de escrita e reescrita de contos a partir da compreensão dos gêneros e tipos textuais e a partir de algumas peculiaridades literárias cultivadas por Clarice Lispector - como a descrição pormenorizada. E, por fim, analisar os resultados da reescrita, com ou sem a correção do professor.

As atividades que são detalhadas a seguir foram desenvolvidas em duas turmas, sendo um universo de 58 alunos (e, portanto, 58 (re)escritas). Para este artigo, entretanto, trabalhamos mais especificamente com dois contos.

Uma das primeiras atividades, que visava apresentar a autora Clarice Lispector e inserir o leitor em seu universo poético, foi organizar a turma em círculo e propor que cada um lesse aleatoriamente um trecho do livro "As palavras", que reúne fragmentos diversos da obra clariceana organizados pelo pesquisador Roberto Corrêa dos Santos.

Entre estilhaços de cartas, contos e romances, os alunos foram entrando no universo da autora e conhecendo uma literatura que, em muitos casos, entende-se 
primeiro com o estômago ou com as veias; para depois, entrever mais racionalmente o que também se quer filosofia, em alguma medida.

O impacto com aquela escrita "estrangeira" foi visível e imediato. "O ovo é a cruz que a galinha carrega". "Que ninguém se engane, só consigo a simplicidade através de muito trabalho". "Porque eu fazia do amor um cálculo matemático errado: pensava que, somando as compreensões, eu amava". A atividade serviu como porta de entrada às muitas faces e fases da importante escritora do século XX.

Para leitura paradidática do trimestre, cada aluno deveria, ainda, adquirir a coletânea "Felicidade Clandestina" de Clarice Lispector. Simultaneamente, o professor promovia, ao longo de quatro semanas, a leitura e a discussão dos contos em sala de aula, assim como exercícios de compreensão e interpretação textual. Dessa forma, tanto as particularidades clariceanas, como o gênero conto foram trabalhados mais detidamente.

Como atividade avaliativa, aos alunos foi proposta, posteriormente, a produção de um texto livremente inspirado em "Restos de carnaval". Por "livremente inspirado", entende-se que os alunos poderiam se apropriar de algum aspecto do conto e recriá-lo. Uma das soluções encontradas por eles foi recontar a história também em $1^{\mathrm{a}}$ pessoa, porém tendo como foco narrativo outro personagem da narrativa. Muitos alunos elaboraram sua escrita nesse caminho: alguns optaram por dar voz ao menino que surge no desfecho, jogando confete e serpentina na protagonista; outros por dar voz à mãe doente ou mesmo ao pai (um tanto ausente) ou, ainda, à irmã. Outras foram as estratégias encontradas por esses alunos: alguns ao descobrirem que o conto nasceu de uma memória muito específica da infância da autora, decidiram narrar uma experiência pessoal vivida no carnaval.

Antes da produção textual em si, que ocorreu em sala de aula, o conto foi lido coletivamente e alguns aspectos foram sublinhados como, por exemplo: a forma como Clarice Lispector dá profundidade aos personagens por meio de descrições pormenorizadas, a maneira como o que é aparentemente banal (como "ir pela primeira vez ao carnaval fantasiada") é transformado num momento de epifania.

Confrontamos também aquele carnaval de Recife, provavelmente, ambientado na década de 30, com as experiências que os alunos tiveram como crianças no carnaval do Rio de Janeiro. E, por fim, construímos uma análise da linguagem utilizada por Lispector. Saltou diante dos olhos a primeira sentença do conto: "não, não deste último carnaval", que é quase uma resposta ao título "Restos de carnaval", mas que não atende 
a nenhuma pergunta específica. Comparamos esse início com a introdução do romance “A paixão segundo G.H.”, na qual a narrativa começa com uma sequência de travessões. Essas escolhas linguísticas foram vistas como uma marca distintiva do labor literário de Clarice Lispector e, ainda, como uma provocação, uma forma de desconstruir uma linguagem previsível e cansada.

Após a elaboração da primeira versão, os textos foram recolhidos e corrigidos. Como tal atividade fazia parte de uma reflexão maior que visava à análise do aluno enquanto autor e leitor de seu próprio texto, adotamos a seguinte estratégia: em uma das turmas, os textos foram entregues com comentários que sugeriam alterações, com a finalidade de proporcionar uma mediação direta do professor; enquanto na outra turma, entregamos os textos sem qualquer comentário, pedindo aos alunos que reescrevessem seu conto a partir de seus próprios critérios. Os resultados foram interessantes.

\section{ESTRATÉGIAS DE REESCRITA DO ALUNO AUTOR-LEITOR}

Selecionamos para análise dois contos, por serem eles muito produtivos às nossas reflexões. Eis, o Conto I.

Como olhar ansioso e admirado segui as pessoas que passavam apressadas pelas ruas, preparando-se para o carnaval. Levavam sacolas cheias de fantasias, adereços e máscaras, preocupadas em se tornarem o mais irreconhecíveis quanto fosse possível.

Eu também fazia compras para o carnaval. Entretanto, ao contrário da maioria das pessoas, estava pensando em gastar todo dinheiro recebido de minha avó em confete e serpentina. Não me importava que meu rosto estivesse exposto e pudesse ser reconhecido - até porque, acredite, não havia ninguém que me reconheceria, além de alguns vizinhos meus avós.

Veja bem, fazia pouco tempo que havia me mudado - e ainda era pouco provável que a mudança fosse definitiva. Meus pais, ambos escritores, haviam finalmente tido a oportunidade de publicar o seu trabalho em conjunto, cultivado durante anos. No entanto, tiveram que viajar até o Rio de Janeiro para realizar esse sonho, deixando-me em Recife aos cuidados de meus avós. Eu estava por eles, era verdade! Mas era um tanto solitário ser deixado em plena época de festa, que era o carnaval. Contudo, estava decidido em tornar essa época em uma lembrança feliz.

Segui pelas ruas carregando o confete e a serpentina que havia comprado - sozinho, pois, segundo meus avós, eles já estavam "velhos demais para isso". Queria arrancar-lhes risadas e fazê-los se divertirem. Mas, sabia que não adiantaria discutir com minha avó, mulher teimosa.

Estava ansioso, já ouvindo as marchinhas típicas, que exalavam alegria e diversão, antes mesmo de chegar no ponto central da festa. Não me importava 
que tivesse que pular carnaval com estranhos, contanto que isso me fizesse esquecer da solidão que me assombrava alguns dias antes.

Algum tempo já havia passado e eu pulava e jogava confete para o alto, sentindo-me alegre de um jeito que havia me sentindo poucas vezes antes. Até que vi uma menina toda vestida de papel crepom, fantasiada de Rosa. Seu olhar cabisbaixo e a postura desanimada fazia contraste como a multidão em êxtase que a envolvia.

Sem pensar muito, corri em sua direção, cobrindo-a de confete e ainda acrescentando um pouco de serpentina. Levou um susto, mas em seu rosto logo brotou um sorriso, e eu soube, quando nossos olhos se encontraram, que não só levei embora a minha melancolia, como também a da menina fantasiada de Rosa.

Ao analisarmos o Conto I, podemos notar que a aluna demonstra uma nítida familiarização com a escrita. Há nele marcas de um amadurecimento literário e gramatical, seja pela composição dos personagens, seja pelas inversões sintáticas, seja pela riqueza vocabular. Poucas seriam as correções, quanto ao registro da norma padrão, como, por exemplo, a substituição da preposição "em" por "a" no trecho "Contudo, estava decidido em tornar essa época...", ou a correção da concordância verbal em "Seu olhar cabisbaixo e a postura desanimada fazia contraste como a multidão", ou, ainda, o acréscimo de vírgula após o adjunto adverbial deslocado na primeira frase do conto.

Entretanto, mais do que apontar esses pequenos deslizes gramaticais, a análise do professor tinha como principal objetivo observar a (re)construção do conto com relação aos elementos narrativos, à coesão e à coerência, mesmo que não existissem claros indícios da necessidade de correção, sinalizados pelo mediador.

Observemos que o diálogo intertextual do Conto I com "Restos de carnaval" alcança o refinamento interpretativo. A aluna capturou a importância das "máscaras" no conto e a ela respondeu. É no terceiro parágrafo de "Restos de Carnaval" que encontramos: "E as máscaras? Eu tinha medo mas era um medo vital e necessário porque vinha de encontro à minha mais profunda suspeita de que o rosto humano também fosse uma espécie de máscara" (1998, p.26) e, ainda, "Fui correndo vestida de rosa - mas o rosto ainda nu não tinha a máscara de moça que cobria minha tão exposta vida infantil" (Ibid., p.28). Note as duas referências logo no início do Conto I, em "Levavam sacolas cheias de fantasias, adereços e máscaras, preocupadas em se tornarem o mais irreconhecíveis quanto fosse possível" e em "não me importava que meu rosto estivesse exposto e pudesse ser reconhecido".

Outro ponto que dialoga com o conto clariceano, por contraste, é a referência ao uso do dinheiro e sua possível escassez ou abundância. Enquanto a protagonista de 
"Restos de carnaval" tinha que economizar com avareza um lança-perfume e um saco de confete; no Conto I, temos: "Eu também fazia compras para o carnaval. Entretanto, ao contrário da maioria das pessoas, estava pensando em gastar todo o dinheiro recebido de minha avó em confetes e serpentinas".

Há ainda outras congruências que foram muito bem trabalhadas pela autora. $\mathrm{O}$ desenvolvimento da narrativa em $1^{\text {a }}$ pessoa foi feito de modo a conferir ao protagonista características para além da superficialidade. O "eu" imprime um tom pessoal e parcial, possibilitando outro ponto de vista e outras criações literárias a partir do enredo proposto por Clarice Lispector.

A melancolia como elo entre os personagens dos dois contos e a "salvação" vivida por ambos no singelo encontro garantem uma nuance interessante no texto da aluna.

Analisemos, a seguir, as alterações propostas pela autora do Conto I (em itálico) em sua segunda versão, e consideremos que este texto estava entre aqueles que não receberam qualquer comentário que sugerisse mudança. A reescrita partiu, então, de uma reflexão mais autônoma da própria aluna e não direcionada.

\section{Máscaras e melancolia}

Como olhar ansioso e admirado segui as pessoas que passavam apressadas pelas ruas, preparando-se para o carnaval. Levavam sacolas cheias de fantasias, adereços e máscaras, preocupadas em se tornarem o mais irreconhecíveis quanto fosse possível.

Eu também fazia compras para o carnaval. Entretanto, ao contrário da maioria das pessoas, estava pensando em gastar todo dinheiro recebido de minha avó em confete e serpentina. Não me importava que meu rosto estivesse exposto e pudesse ser reconhecido - até porque, acredite, não havia ninguém que me reconheceria, além de alguns vizinhos meus avós.

Veja bem, fazia pouco tempo que havia me mudado - e ainda era pouco provável que a mudança fosse definitiva. Meus pais, ambos escritores, haviam finalmente tido a oportunidade de publicar o seu trabalho em conjunto, cultivado durante anos. No entanto, tiveram que viajar até o Rio de Janeiro para realizar esse sonho, deixando-me em Recife aos cuidados de meus avós. Eu estava por eles, era verdade! Mas era um tanto solitário ser deixado em plena época de festa, que era o carnaval. Contudo, estava decidido em tornar essa época em uma lembrança feliz.

Segui pelas ruas carregando o confete e a serpentina que havia comprado sozinho, pois, segundo meus avós, eles já estavam "velhos demais para isso". Queria arrancar-lhes risadas e fazê-los se divertirem. Mas, sabia que não adiantaria discutir com minha avó, mulher teimosa. 
Estava ansioso, já ouvindo as marchinhas típicas, que exalavam alegria e diversão, antes mesmo de chegar no ponto central da festa. Não me importava que tivesse que pular carnaval com estranhos, contanto que isso me fizesse esquecer da solidão que me assombrava alguns dias antes.

Algum tempo depois a atmosfera carnavalesca já me contagiava e sentia-me alegre de um jeito que havia me sentido poucas vezes antes. Até que vi uma menina isolada, com a fantasia de Rosa toda feita em papel crepom. Seu olhar cabisbaixo e costura desanimada faziam um contraste com a multidão em êxtase ao seu redor-por isso a notei.

Em um ato impulsivo, corri em sua direção e a cobri de confete e serpentina. A menina levou um susto, sem dúvida. Mas logo um sorriso brotou em seu rosto, enquanto o papel colorido caía de sua cabeça, tornando-se mais um enfeite ao ficar preso nas dobras do crepom. E eu soube - quando nossos olhos se encontraram - que eu não levei embora apenas a minha melancolia, como também a da menina fantasiada de rosa.

Observemos que nesse momento de reescrita, a autora-leitora criou um título, antes ausente, e optou por desenvolver o sexto e sétimo parágrafos. Embora não tenhamos a preocupação de esgotar as análises possíveis, vamos nos ater a algumas delas.

O trecho "Algum tempo depois a atmosfera carnavalesca já me contagiava e sentia-me alegre" ( $6^{\circ}$ parágrafo) em substituição a "Algum tempo depois já havia passado e eu pulava e jogava confete para o alto, sentindo-me alegre" evidencia um notável ganho literário e expressivo, a nosso ver.

Interessante notar o cuidado em estabelecer nova referência coesiva em "por isso a notei" (final do $6^{\mathrm{o}}$ parágrafo). Parece-nos que, nesse segundo momento, a partir de uma leitura mais atenta e crítica de seu próprio texto foi observada uma lacuna textual, antes ignorada. Mais do que apenas incluir a personagem do conto em seu enredo, houve anseio por justificar essa aparição.

No $7^{\circ}$ parágrafo, o aprimoramento é construído a partir de sequências descritivas - à semelhança da escrita inspiradora do texto. Isso, podemos observar mais especificamente no fragmento: "enquanto o papel colorido caía de sua cabeça, tornandose mais um enfeite ao ficar preso nas dobras de crepom”. O leitor atento e conhecedor do conto "Restos de carnaval" observará que esse detalhe demonstra uma interpretação detida do texto de Lispector pela aluna, já que a fantasia feita de crepom era a metonímia da alegria do carnaval, era a possibilidade de fantasiar-se para ser outra. Logo, o narrador-personagem do Conto I tanto contribuiu para afastar a melancolia da 
menina cobrindo-lhe de confete, como corroborou sua fantasia. Seu gesto simboliza o reconhecimento de que ela era uma rosa.

Por fim, é possível ver algumas correções gramaticais, como a percepção da ausência de plural no verbo "fazer" (linha 28) e outras alterações estilísticas, como a troca de maiúscula por minúscula em "rosa" (última linha) ou a substituição das vírgulas por travessões em "quando nossos olhos se encontraram", dando ao trecho maior destaque.

A experiência de criar espaço para que o aluno fosse o "revisor" de seu próprio conto (e, mais do que isso, pudesse reescrever aquele que fora um primeiro texto elaborado em sala de aula) trouxe felizes resultados, como o que apresentamos acima. Porém, é importante registrar que enquanto alguns alunos se sentiram confortáveis com a proposta e perceberam a atividade como ocasião para aprimoramento de seu trabalho; muitos outros se sentiram solitários e sem norte.

A ausência de comandos perturbou e foi motivo de protesto por alguns. "O que devo mudar?" - muitos insistiam em perguntar, mesmo após as explicações que enfatizavam a autonomia e liberdade diante daquilo que era a criação deles. Esperavam comentários e correções gramaticais, tendo em vista que é a prática escolar mais reiterada.

Em termos bakhtinianos, podemos entrever esse desejo como ligado à necessidade de uma "compreensão responsiva ativa", na medida em que o aluno sempre escreverá para alguém, para outro e dele espera uma reação. Nesse caso, o interlocutor mais imediato e direto será o professor, aquele que também avalia. Nas palavras no teórico:

\footnotetext{
Toda compreensão é prenhe de resposta e, de uma forma ou de outra, forçosamente a produz: o ouvinte torna-se o locutor. A compreensão passiva das significações do discurso ouvido é apenas o elemento abstrato de um fato real que é o todo constituído pela compreensão responsiva ativa (...) o que [o locutor] espera, não é uma compreensão passiva que, por assim dizer, apenas duplicaria seu pensamento no espírito do outro, o que espera é uma resposta, uma concordância, uma adesão, uma objeção, uma execução. (2003, p.290)
}

Convidamos, ainda, o leitor a analisar o Conto II, que está inserido em outra dinâmica de mediação, pois é pertencente à turma que recebeu comentários escritos pelo professor.

\section{Besouro e o palhaço}

$\mathrm{Na}$ maior aleatoriedade do cotidiano, o palhaço serve, basicamente para fazer rir. 
O homem que se pinta para vergonha alheia de alguns, mostra-se triste e sozinho. Sua maquiagem já escorria pelo rosto, fazendo dele um coringa assustador. Embora sua feliz tristeza o deprimisse, foi sem medo algum procurar um amigo. Numa floresta qualquer o risonho achou um pequeno inseto. Ele parecia sozinho, sem ninguém. O palhaço resolveu que não deixaria a impunidade da vida, fazer com que aquele inseto minúsculo, ficasse ali, sem o menor valor. O risadinha se via como um besouro insignificante, sem valor, usado por alguns como objeto de gargalhada. O palhaço estava cansado de ver dentes brancos, aquelas risadas faziam a loucura dele crescer. No momento fora de si, o palhaço come o besouro.

O seu ato dramático fez com que o Risonho contraísse uma doença e nunca mais visse aqueles tais dentes brancos.

O Conto II apresenta uma interessante rede intertextual e acaba por reafirmar a imagem do palimpsesto, pois toda linguagem é sempre permeada de outras vozes. Como bem defendido por Bakhtin:

O próprio locutor como tal é, em certo grau, um respondente, pois não é o primeiro locutor, que rompe pela primeira vez o eterno silêncio de um mundo mudo, e pressupõe não só a existência do sistema da língua que utiliza, mas também a existência dos enunciados anteriores - emanantes dele mesmo ou do outro - os quais seu próprio enunciado está vinculado por algum tipo de relação (fundamenta-se neles, polemiza com eles), pura e simplesmente ele já os supõe conhecidos do ouvinte. Cada enunciado é um elo da cadeia muito complexa de outros enunciados. (2003, p.291)

É por meio da ausência desse mundo mudo anterior que a cadeia de enunciados se manifesta, sempre num intricado complexo de outros enunciados. No Conto II, existe uma evidente alusão ao livro de Clarice Lispector "A paixão segundo G.H.” (apenas citado em sala de aula), em que a personagem esmaga e degusta o interior branco da barata, numa espécie de ascese e de busca epifânica. O título e a presença do besouro retomam o empolgante conto "O barbeiro e o besouro" de Ana Paula Maia, também apresentado e discutido nas aulas de português.

Destacamos esse elemento, porque, embora o Conto II tenha se afastado da temática proposta em "Restos de carnaval", a menção se deu pelo estilo. O aluno priorizou a estratégia clariceana de escrever a partir de um enredo banal, fugindo das narrativas que, carregadas de clichês e ações, despejam tragédias, traições e vinganças.

Há também no Conto II algumas intrigantes escolhas lexicais. Vejamos algumas.

Já na primeira sentença do conto, o aluno propôs " $\mathrm{Na}$ maior aleatoriedade do cotidiano, o palhaço serve, basicamente para fazer rir" ( $1^{\circ}$ parágrafo). Acreditamos que tal seleção vocabular esteja ligada a uma busca pelo "estrangeiro dentro da própria língua" - o que talvez já seja um embrião do fazer literário, que reconstrói e desfaz a 
linguagem. O mesmo movimento podemos perceber em "Embora sua feliz tristeza o deprimisse, foi sem medo algum procurar um amigo" ( $1^{\circ}$ parágrafo). Nesse construir/destruir, porém, o aluno encontrará adeptos ou críticos na medida em que vai se apropriando desse novo fazer linguístico a que se propõe. Parece-nos que, estilisticamente, o paradoxo "feliz tristeza" é mais compreensível do que "aleatoriedade do cotidiano" ou, ainda, está mais costurado ao contexto da narrativa.

Para continuarmos com as análises lexicais, vejamos o fragmento " $\mathrm{O}$ palhaço resolveu que não deixaria a impunidade $d a$ vida, fazer com que aquele inseto minúsculo, ficasse ali, sem o menor valor" ( $2^{\circ}$ parágrafo). Aqui, provavelmente, na tentativa de escrever de forma rebuscada, o aluno elegeu um termo deslocado de seus usos mais correntes, ao optar pela palavra "impunidade". Não encontramos elementos que possamos ligar o besouro a uma "não punição da vida". Por que deveria ser punido? Por que não foi punido? Sobressai a falta de coesão e coerência, com essa escolha vocabular. Isso foi sinalizado ao aluno, que propôs uma adaptação.

Quanto aos aspectos gramaticais, podemos perceber dificuldades na organização dos parágrafos e muitas inadequações quanto à pontuação, o que acaba por sinalizar ao professor uma não compreensão dessas regras e a necessidade de se trabalhar esses aspectos em sala de aula.

Entretanto, consideramos que o problema mais relevante talvez esteja na pressa com que o autor construiu o clímax de seu enredo, quase abortando-o. Curtíssimo, quase passa despercebido de tão pouco desenvolvido.

Chamamos a atenção, por fim, para a coesão nominal feita pelo autor por meio de palavras que tinham por função substituir "palhaço", como "homem que se pinta", "coringa", "risadinha" e "risonho"; dessa forma, fugiu de repetições indesejadas. Porém, como se tratava de uma espécie de nome próprio, seria interessante, para melhor conduzir o leitor, usar os termos em maiúscula.

Vejamos as soluções encontradas pelo aluno na reescrita do Conto II.

\section{$O$ Besouro e o Palhaço}

No pensamento comum, o palhaço serve, basicamente, para fazer rir. O homem que se pinta - para vergonha alheia de alguns - mostra-se triste e sozinho. Sua maquiagem já escorria pelo rosto, fazendo dele um coringa assustador. Embora sua feliz tristeza o deprimisse, foi sem medo algum procurar um amigo.

Numa floresta qualquer, o risonho achou um pequeno inseto. Ele parecia sozinho, sem ninguém. O palhaço resolveu que não deixaria a indiferença do pequeno fazer com que aquele inseto minúsculo ficasse ali, sem o menor valor. 
O risadinha se via como um besouro insignificante, sem valor, usado por alguns como objeto de gargalhada. O palhaço estava cansado de ver dentes brancos, aquelas risadas faziam a loucura dele crescer.

O homem pintado mostrava-se menos consciente com a vida. Ele sentia uma troca de emoções com o besouro. $O$ nariz vermelho sentia uma mistura de emoções, seu estado são, já se fora faz tempo. Ele sentia-se, dentro de sua loucura, um besouro. Eles se viram como iguais. Então, num momento fora de si, o palhaço come o besouro.

$\mathrm{O}$ seu ato dramático fez com que o risonho contraísse uma doença e nunca mais visse aqueles tais dentes brancos.

É possível notar que o aluno imprimiu várias alterações, segundo as sugestões feitas pelo professor (quebra de parágrafo, pontuação, substituição de expressões sublinhadas, desenvolvimento do clímax).

Diante da proposta de substituição de "não deixaria a impunidade da vida" $\left(2^{\circ}\right.$ parágrafo), o aluno criou "não deixaria a indiferença do pequeno", o que de fato se adequou melhor ao contexto, tendo em vista que havia incoerência em dizer que "o besouro não havia sido punido pela vida". Parece-nos que, de fato, o autor havia se confundido, na sua primeira versão. A substituição de "Na maior aleatoriedade do cotidiano" por "No pensamento comum" ( $1^{\circ}$ parágrafo), entretanto, acabou eliminando certa potência anterior, apesar do tom artificial de outrora.

Já o fragmento "No momento fora de si, o palhaço come o besouro" (final do $4^{\circ}$ parágrafo) ganhou sequências descritivas mais detalhadas - o que contribuiu para maior desenvolvimento do que ele propôs como clímax.

Por fim, sinalizo a ambiguidade do trecho "Ele parecia sozinho, sem ninguém" ( $2^{\circ}$ parágrafo), após a inserção de "indiferença do pequeno". Observe que o pronome pessoal que funcionava apenas como referência anafórica, retomando "um pequeno inseto", acaba também por se ligar ao "palhaço" (referência catafórica), que igualmente está solitário e sofre com a apatia do inseto. Essa ambiguidade pode ser lida como produtiva, na medida em que o autor quer tornar um o palhaço e o besouro e o faz expressamente em "Ele sentia-se, dentro de sua loucura, um besouro. Eles se viram como iguais" ( $4^{\circ}$ parágrafo).

A partir dessas experiências de reescrita, muitas são as análises construídas. Perceber como os alunos demonstram diferentes níveis de amadurecimento gramatical e distintas formas de se apropriar de seu próprio texto por meio da reescrita são dois exemplos. Observar como o texto literário foi lido e percebido e, ainda, como gerou novos textos permitirá, sem dúvidas, futuros artigos e novas pesquisas. 


\section{CONSIDERAÇÕES FINAIS}

Quando optamos por ponderar a reescrita através de duas dinâmicas distintas, uma com comentários pelo professor e outra marcada pelo silêncio, objetivávamos possibilitar dois contextos diferentes de pesquisa. Alguns resultados puderam ser percebidos.

Enquanto, na reescrita do Conto I, sobressaiu a autonomia ou a percepção linguística da aluna; na reescrita do Conto II, observamos que o aluno alterou apenas o que havia sido indicado pelo professor. Esse fato gerou algumas perguntas e reflexões: tal atitude demonstraria que estamos diante de um aluno que quer atender às expectativas ligadas à avaliação, mais do que construir seu texto autonomamente? Sua postura de "sujeito" caminha em que sentido? Seria possível que esse aluno sentisse legitimidade para alterar o que ele próprio julgasse como necessário, para além do que a voz de autoridade do professor imprimiu?

Ao resgatarmos a reflexão bakhtiniana de que buscamos sempre uma "compreensão responsiva ativa" por meio do que escrevemos e falamos, podemos entrever uma expectativa do aluno em atender ao seu interlocutor, no caso o professor/leitor.

Dentro desse contexto, é importante que o professor promova, em sua prática de análise e correção textual, interferências equilibradas com o estímulo à autonomia e à criatividade. Dessa forma, caminhamos na construção de escritas cada vez mais críticas e inventivas.

\section{REFERÊNCIAS}

BAGNO, Marcos. Gramática pedagógica do português brasileiro. São Paulo: Parábola Editorial, 2012.

BAKHTIN, Mikhail. Estética da criação verbal. (Introdução e tradução do russo por Paulo Bezerra) São Paulo: Martins Fontes, [1979], 2003.

FREIRE, Paulo. Pedagogia da Autonomia: saberes necessários à prática educativa. São Paulo: Paz e Terra, 1996.

LISPECTOR, Clarice. A paixão segundo G.H. 1ed. Rio de Janeiro: Rocco, 1998. 
Janeiro: Rocco, 2013.

As palavras. Curadoria: Roberto Correa dos Santos. Rio de

. Felicidade Clandestina. 1ed. Rio de Janeiro: Rocco, 1998.

MARCUSCHI, Luiz Antônio. Gêneros textuais: definição e funcionalidade. In: . Gêneros textuais: constituição e práticas sociodiscursivas. São Paulo:

Cortez, 2010.

\section{A AUTORA}

Sabrina Alvernaz Silva Cabral é mestre em Estudos da Linguagem pela PUC-Rio e professora efetiva do Colégio Pedro II, no Rio de Janeiro. Escreveu o livro "Sangue, cauim e cerveja: a metáfora em Jorge Luis Borges à luz do perspectivismo ameríndio" (2015).

E-mail: sabrinaalvernaz@yahoo.com.br 